\title{
Surface-tectonic coupling at the Namche Barwa - Gyala Peri massif and geologic hazards associated with a proposed dam on the Yarlung-Tsangpo river in SE Tibet
}

\author{
Peter Zeitler ${ }^{1 *}$, Anne Meltzer ${ }^{1}$, Brian Zurek ${ }^{1}$, Lucy Brown ${ }^{1}$, Noah Finnegan², Bernard Hallet ${ }^{3}$, \\ Page Chamberlain ${ }^{4}$, William Kidd ${ }^{5}$ and Peter Koons ${ }^{6}$ \\ 1 Dept. of Earth and Environmental Sciences, Lehigh University, Bethlehem, PA 18015, USA \\ 2 Dept. of Earth and Atmospheric Sciences, Cornell University, Ithaca, NY 14853, USA \\ 3 Dept. of Earth and Space Sciences, University of Washington, Seattle, WA 98195, USA \\ ${ }^{4}$ Dept. of Geological and Environmental Sciences, Stanford University, Stanford, CA 94305, USA \\ 5 Dept. of Earth and Atmospheric Sciences, University at Albany, Albany, NY 12222, USA \\ 6 Dept. of Earth Sciences, University of Maine, Orono, ME 04669, USA \\ * For correspondence,email: peter.zeitler@lehigh.edu
}

The Yarlung-Tsangpo River leaves the SE Tibetan Plateau through a deep canyon that it slices across the Himalaya as it drops $\sim 2000$ $\mathrm{m}$ along an irregular hairpin reach $\sim 100 \mathrm{~km}$ in length. We have been examining the geodynamic evolution of this region and have gathered considerable geophysical and geological data on this steep reach of the river and the surrounding Namche BarwaGyala Peri massif. In this region, petrological, geochronological, thermochronological, and cosmogenic-isotope data show that very rapid bedrock exhumation at rates of $7 \mathrm{~mm} / \mathrm{yr}$ or more has exposed granites as young as $1 \mathrm{Ma}$, and this rapid exhumation has been underway for at least the past 3 m.y.

Detrital-dating evidence shows that these high rates continue at present and that erosion within the massif contributes fully $50 \%$ of the modern suspended-sediment load in the Yarlung-Tsangpo at the point where it enters the Assam floodplain (roughly 100 $\mathrm{Mt} / \mathrm{yr}$ of sediment are derived from the massif). The steep slopes in the massif fail by pervasive landsliding and suggest a steadystate topography where the high erosion rates are balanced by equivalent rates of rock uplift accommodated by numerous active structures.

At a broader scale, GPS results show that steep threedimensional velocity gradients exist across the region: in the easternmost Himalaya near Namche Barwa $>50 \%$ of the Indian - Eurasian plate convergence is accommodated within a zone of high strain rates. The 1950 Assam earthquake (M8.6) was one expression of the high local strain rates, and caused considerable damage within the canyon area. Seismic results from our portable deployment show that the area beneath the massif and the Yarlung-Tsangpo canyon is exceptionally active, with over 1000 events ranging in magnitude from 1.0 to $5.6(\mathrm{mb})$ taking place over a 15 -month period. The events occur almost entirely in the mid to shallow crust and show a range of first motions.
Dynamical modeling and context provided by diverse regional data suggests that the metamorphic massif and steep reach of the Yarlung-Tsangpo at Namche Barwa have persisted for at least 3 m.y. Divergent low-temperature cooling histories within and upstream of the massif suggest that development of a coupled system and pinned knickpoint may have started at roughly $5 \mathrm{Ma}$.

For a decade anecdotes and media reports have been circulating about a proposed dam in SE Tibet, on the YarlungTsangpo knickzone. The fundamental purpose of the dam is generation of $\sim 40,000 \mathrm{MW}$ of hydropower to be used in diverting a portion of the impounded river to water-starved regions of northern China. It has been argued that any benefits that would accrue from improving water supply in the north would be offset by water-flow and sediment-flux impacts that would be felt downstream in the Brahmaputra system in northeastern India and Bangladesh, as well as by the impacts that a dam and large lake would have on the pristine, ecologically and ethnographically diverse area around the Yarlung-Tsangpo canyon, an area of great significance to Tibetan Buddhists.

Our data show that the Yarlung-Tsangpo canyon is one of the most geologically active regions on Earth, and they suggest that any dam placed there would be at high risk, with the dam being prone to failure due to pronounced seismic hazards and focused deformation. As it fills, water pressure behind the dam could help trigger shallow earthquakes and landslides, and the dam would be difficult to maintain given the high frequency of landsliding and extreme local bedrock exhumation rates that would lead to rapid siltation at the dam site. Further, this impoundment of the Yarlung-Tsangpo would greatly starve the sediment flux downstream in the Brahmaputra, its densely populated flood plain, and ultimately the Bay of Bengal systems. 